Originales

\title{
PKB/Akt media la radio sensibilidad asociada a Ataxia Telangiectasia
}

\author{
J. Guinea Viniegra ${ }^{1}$, N. Martínez ${ }^{1}$, C. I. Aceves Luquero ${ }^{1}$, E. Galán Moya ${ }^{1}$, M. A. de la Cruz ${ }^{1}$, \\ J. L. Callejas Valera' ${ }^{1}$ A. Arraiga Aragón¹, C. Ramírez-Castillejoํ, M. V. Villas Sánchez ${ }^{2}$, \\ J. M. Rojas ${ }^{3}$, R. Sánchez-Prieto ${ }^{1}$
}

\section{Resumen}

El gen mutado en el síndrome de Ataxia Telangiectasia está implicado en múltiples funciones celulares que abarcan desde la respuesta al daño genotóxico causado por la radiación ionizante hasta la respuesta a insulina. Curiosamente la ruta de señalización mediada por Akt esta relacionada con los mismos estímulos. En el presente estudio demostramos como el gen mutado en Ataxia Telangiectasia (ATM) controla la fosforilación de Akt, en respuesta a estímulos como la radiación ionizante o la insulina. Estos datos han sido obtenidos usando modelos experimentales como células derivadas de enfermos de Ataxia o de ratones nulos para la expresión de ATM. Nuestro estudio propone nuevas explicaciones para entender la radio sensibilidad característica de estos enfermos y destaca el papel primordial de Akt en la respuesta a la radiación ionizante.

\section{Palabras clave:}

ATM. Akt radiosensibilidad.

Oncología, 2005; 28 (7):329-337

\footnotetext{
${ }^{1}$ Laboratorio de Oncología Molecular CRIB. Facultad de Medicina, UCLM. Albacete

${ }^{2}$ Unidad de Biología Celular. Centro Nacional de Microbiología. Instituto de Salud Carlos III. Majadahonda (Madrid)

${ }^{3}$ Unidad de Radioterapia. Complejo Hospitalario Universitario de Albacete
} 


\section{Summary}

The gene mutated in ataxia telangiectasia (ATM) has been implicated in several functions such as cell cycle, response to DNA damage, and insulin. Curiously, the PKB/Akt-mediated signaling route is related to the same cellular responses. We show in this work that ATM is a major determinant of full PKB/Akt activation in response to insulin or $\gamma$-radiation. This conclusion was inferred from the results obtained in transient transfection assays using exogenous PKB/Akt and ATM in Cos cells, and also in cell lines derived from ataxia telangiectasia patients or $\mathrm{KO}$ mice. Our study proposes new clues to understand the radiosensitivity associated to ataxia telangiectasia and supports a critical role for $\mathrm{PKB} / \mathrm{Akt}$ in the cellular response to ionizing radiation.

Key words: Ataxia telangiectasia. ATM. Akt. Radiosensitivity.

\section{Introducción}

La enfermedad de Ataxia Telangiectasia (AT) es un síndrome autosómico recesivo que se caracteriza por un retraso del crecimiento, ataxia cerebelar, susceptibilidad al cáncer, telangiectasia ocular, inmunodeficiencia grave, resistencia a insulina e hipersensiblidad a la radiación gamma entre otros síntomas (para revisión consultar) ${ }^{1}$.

En el nivel celular, el gen mutado en Ataxia Telangiectasia (ATM) participa en un amplio espectro de procesos biológicos que incluye control del ciclo celular, estabilidad del genoma, mecanismos de apoptosis y respuesta a estrés genotóxico, entre otros $^{2-5}$. La proteína codificada por el gen ATM pertenece a la superfamilia de las fosfatidil-inositol-3quinasas (PI3K) al presentar un dominio similar al de la subunidad catalítica p110, pero hasta el momento no se ha demostrado su actividad lípido quinasa $^{6}$. Dicho dominio es responsable de la fosforilación de proteínas como p53, ChK1, 4EBP y BRCA1 en el motivo conservado -S/T-Q- en el cual S o T actúan como residuos fosfoaceptores (para revisión consultar) ${ }^{7}$. Es destacable el hecho de que el propio ATM se regula por autofosforilación en el residuo Serina 1981, con igual motivo (-S/T-Q-) al de sus sustrato, como se ha publicado recientemente ${ }^{8}$.

La proteína PKB/Akt, referida como Akt en adelante, es un actor clave en una de las rutas de supervivencia celular, mediante la inhibición de señales apoptóticas y su papel en la activación del ciclo celular, con una implicación clara en cáncer y otras patologías ${ }^{9,10}$.

Por otra parte, se ha demostrado que Akt se activa potentemente en respuesta a diversos factores de crecimiento como insulina o IGF-1, y asimismo en respuesta a daño en el $\mathrm{ADN}^{11}$, 12. Parece que para la completa activación es crítica la fosforilación en los residuos Thr 308, mediada por PDK1, y Ser473 mediada por una proteína aún no caracterizada llamada PDK2) $)^{13}$.

Curiosamente, estas dos rutas de transducción de señales en apariencia independientes, parecen converger en el plano fisiológico cuando responden a estímulos como insulina o radiación gamma. De hecho, modelos animales 'Knock Out' (KO) para Akt y ATM muestran similitud en anormalidades fenotípicas como retraso del crecimiento, defectos en la maduración del sistema inmunitario, infertilidad, resistencia a insulina o radiosensibilidad ${ }^{14,16}$.

En el presente trabajo se explora la posible conexión entre estas dos vías de acción dependientes de Akt y ATM, y si esta relación permite avanzar en el entendimiento de propiedades biológicas como la radiosensibilidad y la resistencia a insulina, observadas en la enfermedad de la Ataxia Telangiectasia.

\section{Materiales y métodos}

\section{Líneas celulares}

Las líneas GM00637, GM09607 y GM08391 fueron cedidas por el Instituto Coriell para la investigación Biomédica (Candem, NJ). MEF procedentes de animales Knock Out para p53 (p53 -/-,ATM +/+) llamados KO p53, y también el doble Knock Out para p53 y ATM (p53 -/-,ATM -/-) denomindos como DKO fueron generosamente donados por el Dr. 
Philip Leder (HHMI, escuela médica de Harvad, Boston, MA, 02115). Las células IMR90 junto con las anteriores fueron mantenidas en DMEM con $10 \%$ de suero fetal bovino (Biowhittaker, Verviers, Belgium) en $5 \% \mathrm{CO}_{2}$ a $37^{\circ} \mathrm{C}$.

\section{Plásmidos y transfecciones}

Se han utilizado los siguientes plasmidos: Flag-6His ATM (wt) en el vector PEBS7-YZ5 cedidos por el Dr. Y. Silo (Universidad de Tel Aviv, escuela de medicina, Israel). Akt wt marcado con hemaglutinina(HA), kinasa inactivo y miristoilado en el plásmido pCEFL, fueron amablemente cedidos por el Dr. S. Gutking (NIDCR, NIH, Bethesda, MD). Las transfecciones se realizaron con lipofectamina y posteriormente las células fueron seleccionadas con G418 o hygromicina .

\section{Anticuerpos, Western blot e inmunoprecipitaciones}

Se han utilizado los siguientes anticuerpos:

El fosfo-anticuerpo específico contra la Ser 473 de Akt fue obtenido de Cell Signaling Technologies (CST, Beverly, MA). Los anticuerpos contra Akt IR $\alpha$ y HA fueron obtenidos de Santa Cruz Biotech (Santa Cruz, CA). Los ensayos quinasa de Akt se desarrollaron con un kit no radiactivo de CST. Para los ensayos de fosforilación de Akt, las células fueron tratadas y recolectadas en buffer de lisis $(25 \mathrm{mM}$ Hepes pH 7.5, 0.3 M NaCl, $1.5 \mathrm{mM} \mathrm{MgCl} 2,0.2$ mM EDTA, $1 \%$ Triton $X-100,0.1 \%$ SDS, $0.5 \%$ Ácido Deoxicólico, $20 \mathrm{mM} \beta$-glicerolfosfato) en presencia de inhibidores de proteasas y fosfatasas (20 $\mu \mathrm{g} / \mathrm{ml}$ aproteinina, $20 \mu \mathrm{g} / \mathrm{ml}$ leupeptina, $1 \mathrm{mM}$ PMSF, $0.1 \mathrm{mM}$ Na3VO4, $20 \mathrm{mM}$ NaF y $1 \mathrm{mM} \mathrm{NaP}$ $\mathrm{Pi})$. Los lisados fueron recogidos en el mismo tampón que en los ensayos quinasa y procesados por Western blot (normalmente $50 \mu \mathrm{g}$ ) o mediante inmunoprecipitación usando anticuerpos específicos y proteína G (Amershan Pharmacia). Los inmunocomplejos se lavaron y resuspendieron en un buffer de carga 5x. La detección del anticuerpo se realizó por quimioluminiscencia (ECL, Amersham Pharmacia, Uppsala, Sweden).

\section{Tratamientos}

Las células fueron tratadas con insulina Novo
Nordisk (Bagsvaerd, Denmark) durante 30 minutos a las dosis indicadas. Las células se sometiron a radiación gamma usando una fuente de cobalto (Theratron $780 \mathrm{AECL}$, Canada) a un SSD de $57 \mathrm{~cm}$ y una tasa de $285 \mathrm{cGy} / \mathrm{min}$. Las células se mantuvieron a $37^{\circ} \mathrm{C}$ y $5 \% \mathrm{CO}_{2}$ durante 7 días tras la radiación en los ensayos de viabilidad y durante 30 minutos en los ensayos quinasa. Los pre-tratamientos con cafeína (Sigma) fueron a una dosis de $2 \mathrm{mM}$ durante 1 hora en los casos indicados. La selección de transfectantes estables se realizo por higromicina (Roche) a dosis de $50 \mu \mathrm{g} / \mathrm{ml}$ o G418 (Sigma) a dosis de $750 \mu \mathrm{g} / \mathrm{m} .1$

\section{Citometría de flujo}

Las células fueron lavadas con PBS y fijadas durante 30 minutos con etanol al $70 \%$ a $-20^{\circ} \mathrm{C}$. Después fueron nuevamente lavadas resuspendidas en 1 $\mathrm{ml}$ de PBS con ioduro de propidio $(10 \mu \mathrm{g} / \mathrm{ml})$ y RNAsa $(20 \mu \mathrm{g} / \mathrm{ml})$. Las muestras fueron analizadas con Epics XL (Coulter Electronics). Aquellas células con DNA con menor marcaje que la población celular en G1 son consideradas como apoptóticas (pico sub-G1).

\section{Resultados}

\section{Las líneas celulares derivadas de pacientes de AT o de ratones nulos para ATM son incapaces de fosforilar la serina473 de Akt en respuesta a insulina}

En un primer intento, usamos insulina, un potente activador de Akt, en un modelo experimental de células GM08931 (fibroblastos derivados de un paciente con AT), usando como control células IMR90. Las células se incubaron en medio sin suero durante toda una noche para evaluar la fosforilación de la Ser473 de Akt. Las células que carecían de la proteína ATM mostraban un claro descenso de la fosforilación sobre la serina473 respecto a la línea control tras tratamiento con insulina (Fig. 1a). Sin embargo, como el fondo genético entre las IMR90 y las GM08931 puede ser muy diferente, decidimos usar otra línea celular derivada de otro paciente y de un hermano heterocigoto, GM09607(-/-) y GM00637(-/+). Para asegurarnos de si las diferencias observadas eran debi- 


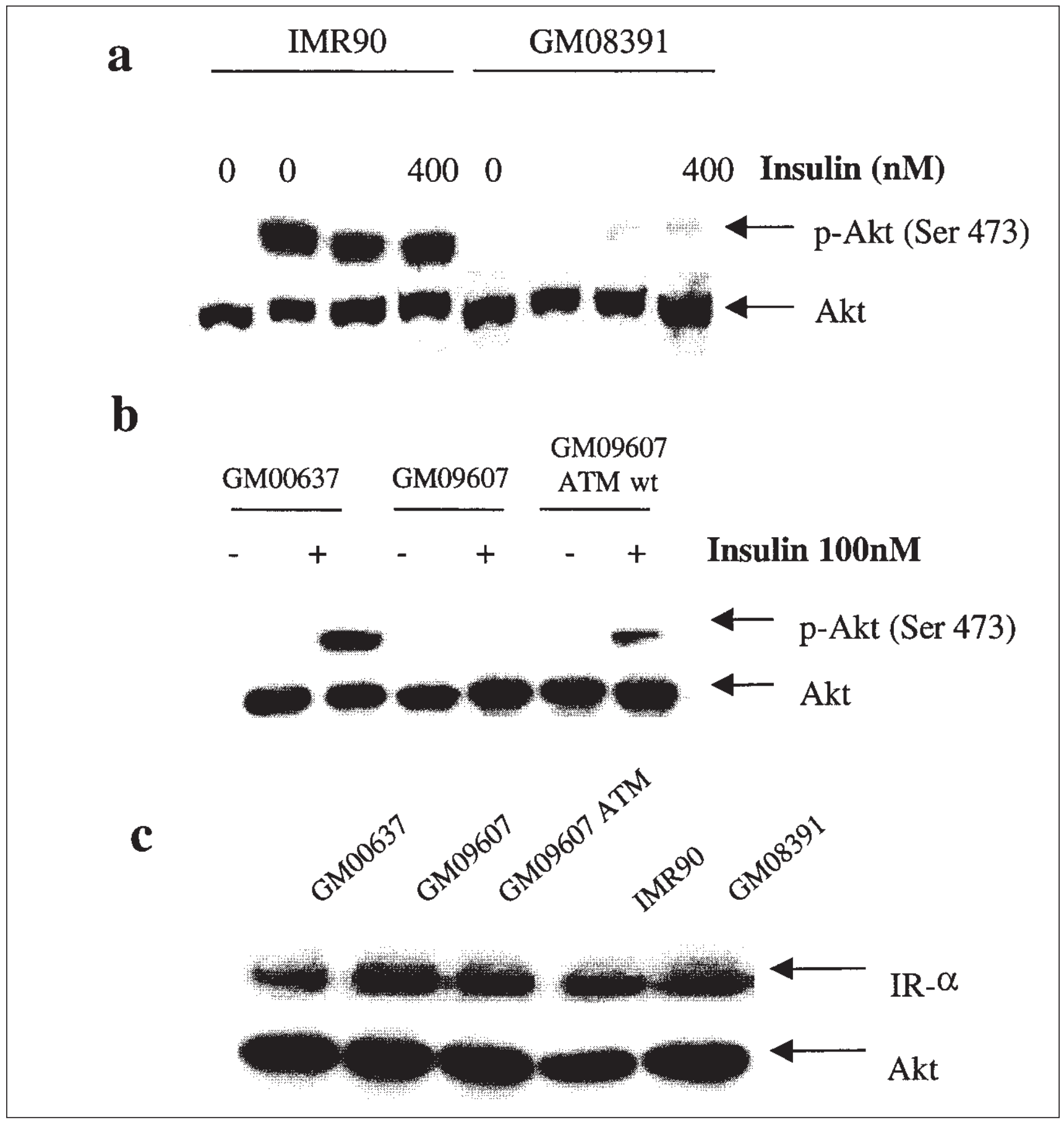

Figura 1. Las líneas celulares derivadas de pacientes de AT son defectivas en la fosforilación de la serina 473 de AKT en respuesta a insulina.

a) Las líneas celulares IMR90 y GM08391 se trataron durante 30 minutos con cantidades crecientes de insulina y posteriormente se evaluó la fosforilación de AKT en la serina 473. Se usó AKT total como control de carga.

La figura muestra un inmunoblot representativo de una serie de tres experimentos

b) Las líneas celulares GM00637, GM09607 y GM09607 Atm wt que expresa ATM tipo salvaje se trataron con insulina y se evaluó la fosforilación de Akt endógeno. Se usó Akt total como control de carga. la figura muestra un inmunoblot representativo de una serie de tres experimentos

C) Se midieron los niveles de la subunidad a del receptor de insulina. Como control de carga se utilizo los niveles totales de Akt. La figura muestra un inmunoblot representativo de una serie de tres experimentos 


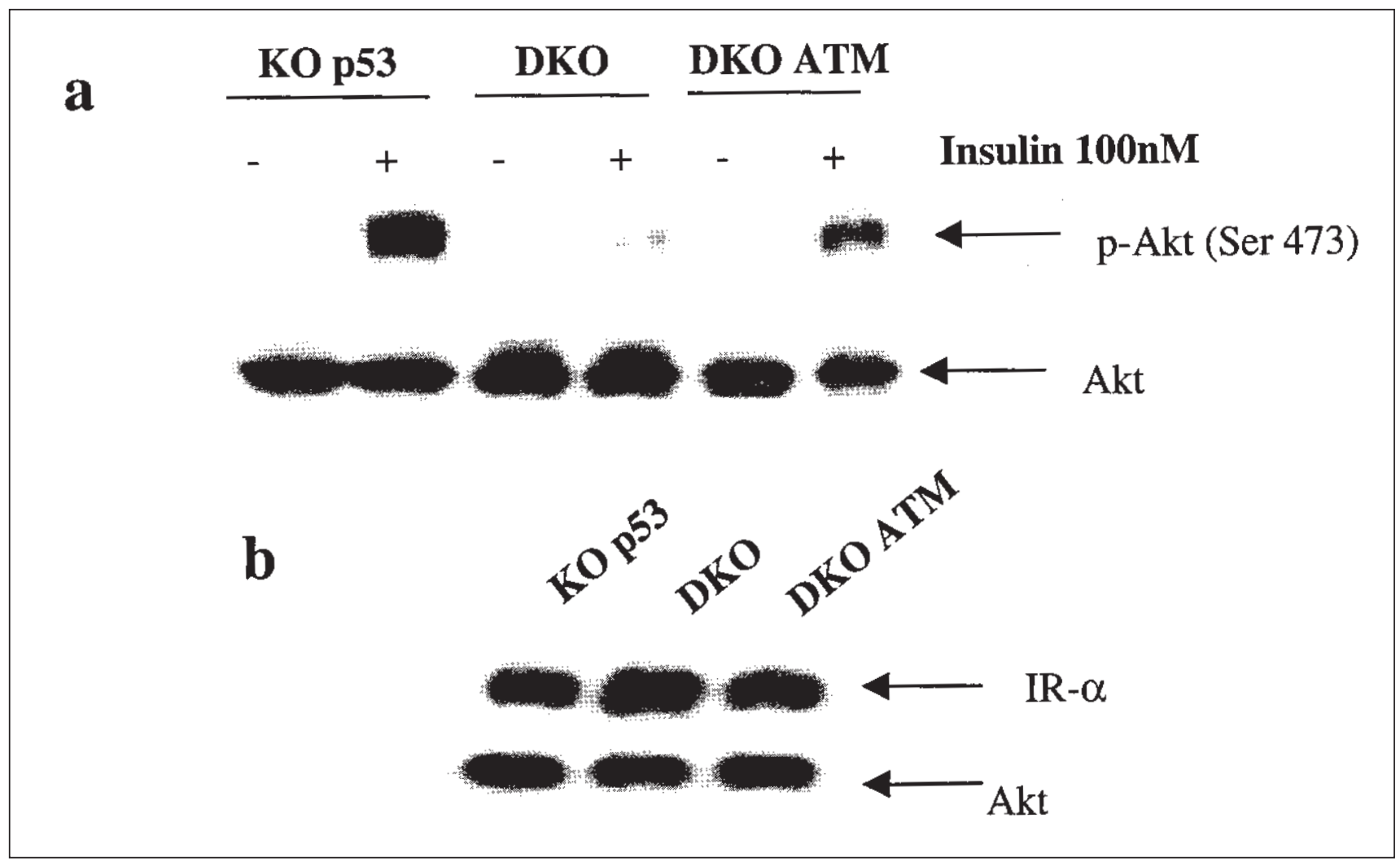

Figura 2. Las células KO para ATM son defectivas en la fosforilación de la serina 473 de Akt en la respuesta a insulina.

A) Las líneas celulares KO (p53 -/-, ATM +/+), doble KO (p53 -/-, ATM -/-) y doble KO ATM fueron incubados con Insulina 100nM durante 30 minutos y posteriormente se evaluó la fosforilación en la Serina 473 de akt. al igual que en la figura 1 se tomo como control carga el nivel total de Akt. la figura muestra un inmunoblot representativo de una serie de tres experimentos

B) Evaluación los niveles de la subunidad a del receptor de insulina. Como control de carga se utilizo los niveles totales de Akt. La figura muestra un inmunoblot representativo de una serie de tres experimentos

das específicamente a la falta de expresión de ATM, transfectamos ATM salvaje en las células deficientes de AT. Como esperábamos, en las líneas celulares en las que sobre expresamos el ATM ectópico se reestablecía la fosforilación de la Ser473 (Fig. 1b). Para excluir que el receptor de insulina o alguno de los intermediarios estuviera afectado en las células deficientes para ATM, medimos los niveles del receptor de insulina (IR) y la funcionalidad de la vía. No se observó ninguna diferencia en los niveles de expresión de RI (Fig. 1c). Sin embargo, nuestras primeras observaciones podrían ser debidas a diferentes respuestas específicas en nuestros modelos experimentales (dos líneas celulares con diferente fondo genético respecto de su control). Por consiguiente, decidimos usar un modelo biológico con idéntico fondo genético idéntico como pueden ser los fibroblasto murinos embrionarios (MEF) derivados de ratones nulos para ATM y sus correspondientes controles ${ }^{17}$. De nuevo, se obtuvieron los mismos resultados en términos de fosforilación de Akt, funcionalidad de la vía y expresión de los RI (Fig. 2a, b). De hecho, la reinstauración de la expresión de ATM fue capaz de recuperar la fosforilación de la serina473 (Fig. 2a, b).

\section{La activación defectiva de Akt correlaciona con la radio sensibilidad asociada a AT}

El uso de un solo estímulo (insulina) no permite proponer un mecanismo general en el que ATM esté controlando la actividad de Akt. Por tanto, probamos otro estímulo bien descrito para ATM, como es la radiación ionizante. Para ello las células GM09607 y GM00637 fueron sometidas a radiación ionizante y posteriormente analizadas mediante ensayo quinasa "in vitro" para comprobar la actividad de Akt. En las células de AT se detectó una falta de 
a
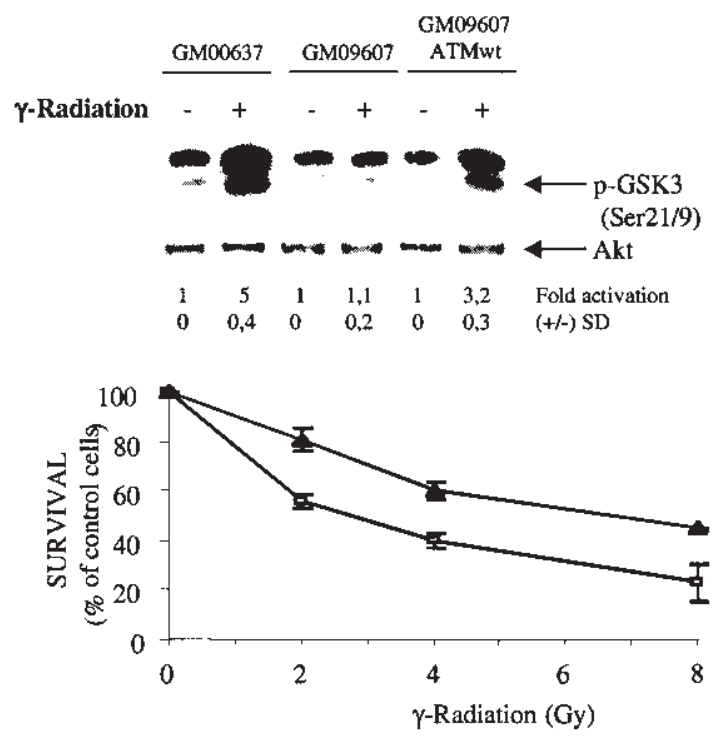

b
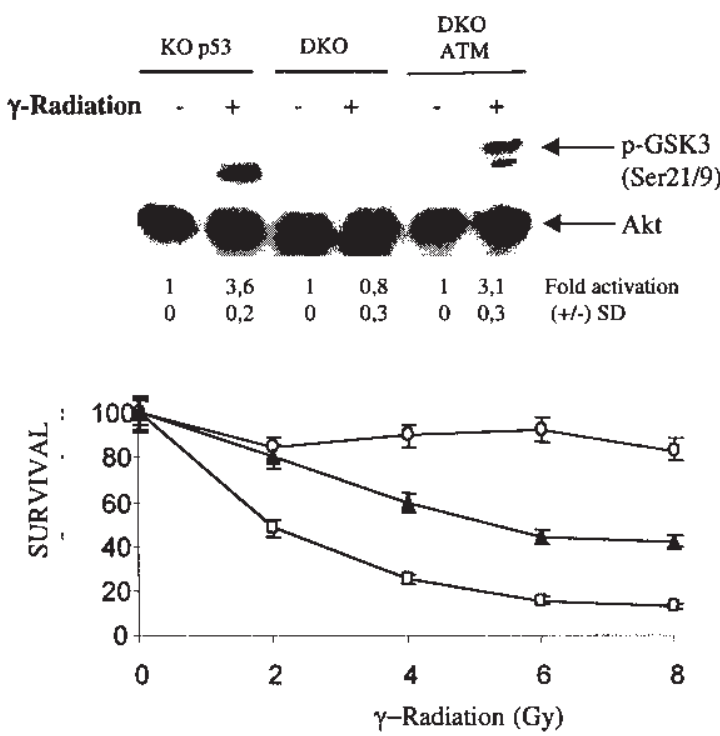

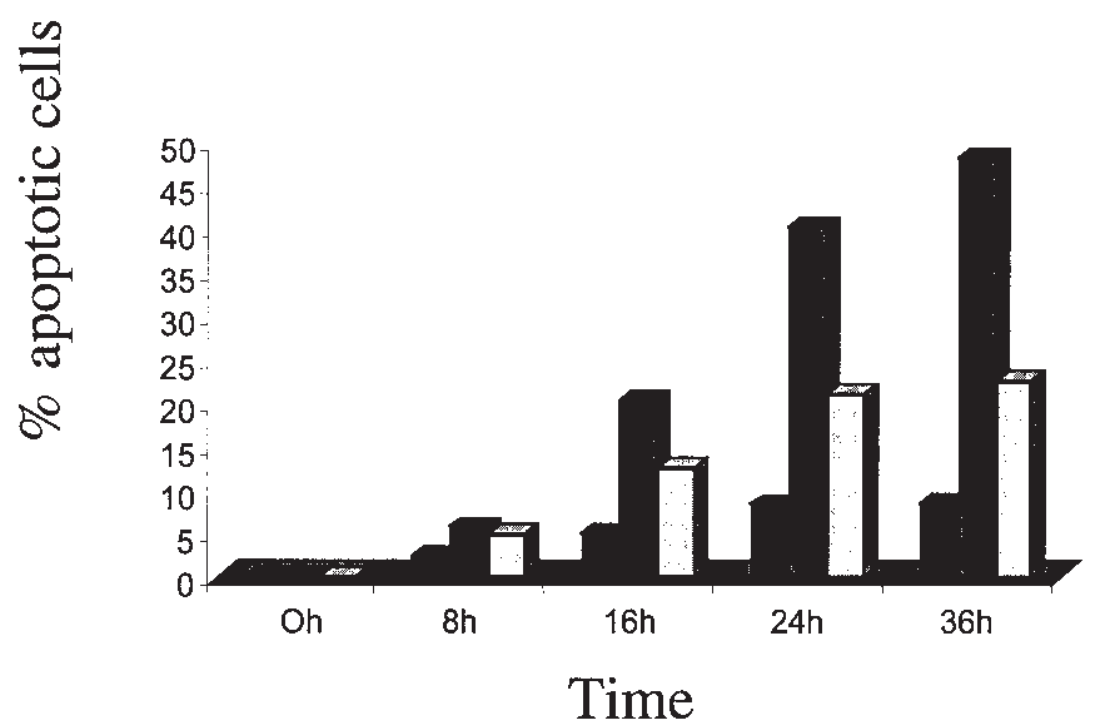

Figura 3. La falta de actividad de Akt correlaciona con un fenotipo sensible a la radiación ionizante.

A) Ensayo quinasa in vitro de la actividad de Akt en células GM00637, GM09607 y GM09607 expresando ATM (salvaje 9607 ATM wt) 30 minutos después de una exposición de $20 \mathrm{~Gy}$. Los valores (unidades arbitrarias) fueron normalizados respecto a los niveles de Akt total determinado por inmunoblot. Se muestra un experimento representativo de tres. SD =desviación estandar. Curva de dosis repuesta a radiación ionizante en células GM09607 ( $\square$ ) y GM09607 expresando ATM wt (A). las células fueron irradiadas a diferentes dosis y la viabilidad se evaluó a los 7 días. Los resultado muestran la media con desviaciones estándar de tres experimentos. (panel inferior).

B) Ensayo quinasa in vitro de la actividad de Akt en KO p53, DKO, or DKO ATM expresando ATM salvaje (DKO ATM wt) 30 minutos después de una exposición de 20 Gy. Los valores (unidades arbitrarias ) fueron normalizados respecto a los niveles de Akt total determinado por inmunoblot. Se muestra un experimento representativo de tres. SD =desviación estándar. Curva de dosis repuesta a radiación ionizante en células KO $(\mathrm{O})$, DKO $(\square)$ or DKO ATM $(\mathbf{\Delta})$. Las células fueron irradiadas a diferentes dosis y la viabilidad se evaluó a los 7 día. Los resultado muestran la media con desviaciones estándar de tres experimentos. (panel inferior).

C) evaluación de apoptosis tras irradiación con 8 Gy en células KO (p53 -/-, ATM +/+), Doble KO (p53 -/-, ATM -/-) y DKO ATM expresando ATM salvaje. 


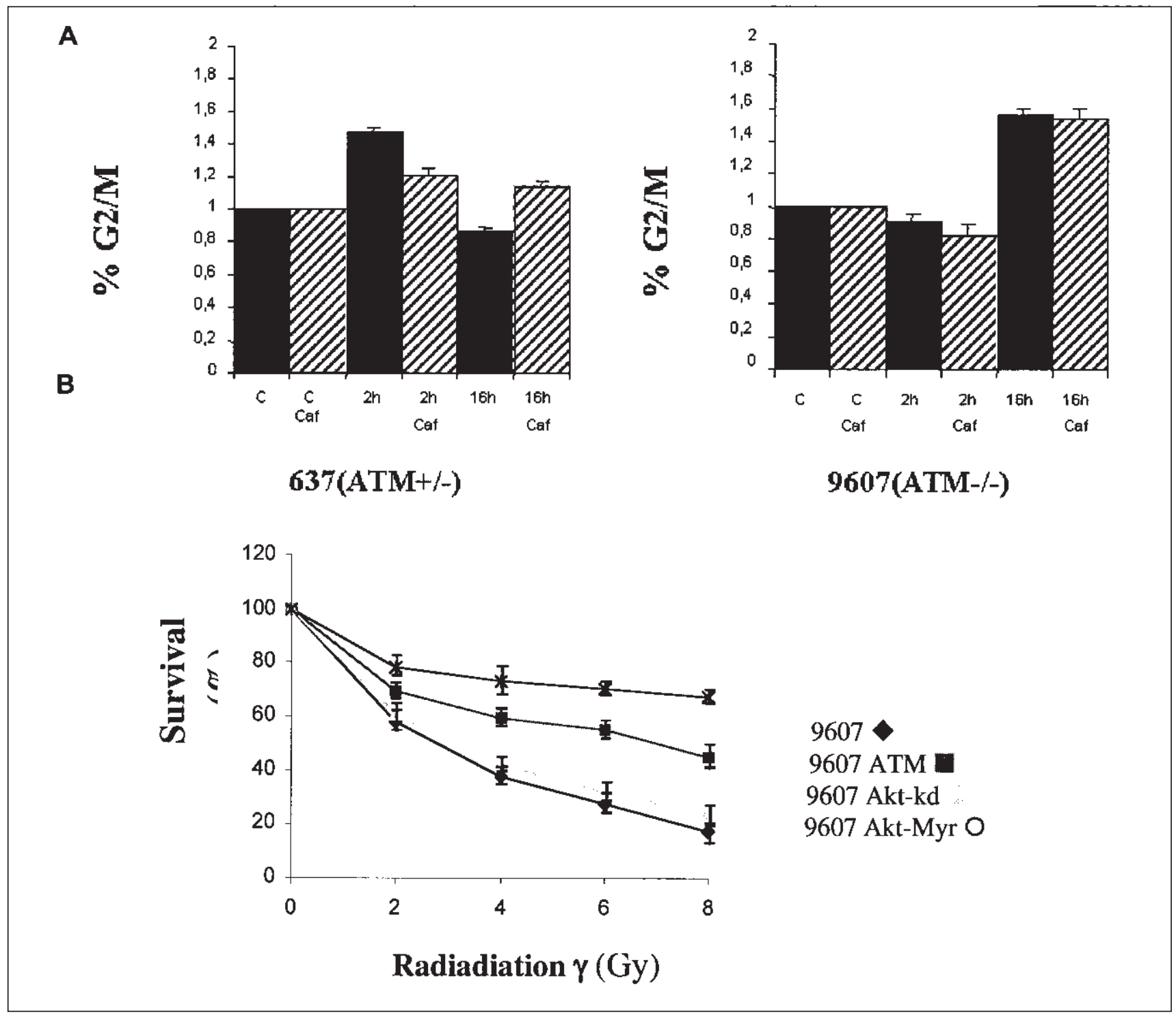

Figura 4. Papel de Akt en la respuesta a radiación ionizante en células derivadas de enfermos de AT

A) las células GM00637, GM09607 fueron irradiadas con 8 Gy y se evaluó el porcentaje de celulas en G2/M por citometría de flujo a diferentes tiempos en presencia/ausencia de cafeína $(100 \mathrm{mM})$ una hora antes de la irradiación

B) la células GM09607 fueron establemente transfectadas con una forma hiperactiva (MYR) o una forma inactiva (KD) de Akt. Tras dos semanas de selección con G418 se realizaron ensayos de viabilidad como los descritos en la figura 3Ay 3B.

actividad de Akt que correlacionaba con un fenotipo sensible y que se revertía por sobreexpresión de ATM salvaje exógeno (Fig. 3a). Los mismos resultados se obtuvieron en el modelo derivado de células KO (Fig. 3b). También evaluamos la respuesta apoptótica a la radiación ionizante en este modelo experimental. Este dato apoya el papel crítico que tiene la activación de Akt en respuesta a radiación a través del control de la inhibición de la maquinaria apoptótica.

\section{Papel de Akt en el ciclo celular y supervivencia en una línea celular derivada de un paciente de AT}

Todos nuestros resultados indicaban una correlación entre la falta de activación de Akt asociada a una disfunción de ATM y la respuesta celular a radiación ionizante: Entonces, decidimos evaluar el papel de la inhibición de ATM respecto del punto de control G2/M del ciclo celular. Este punto de 
restricción del ciclo celular está fuertemente regulado por Akt y curiosamente, es defectivo en células deficientes para ATM. Así, células GM637 y GM9607 fueron pre-tratadas con cafeína, un potente inhibidor de ATM, y luego irradiadas evaluándose posteriormente la fase G2/M mediante ensayos de citometría de flujo (Fig. 4a). Las células ATM positivas eran sensibles a la cafeína y mostraban un incremento de la fase G2/M del ciclo celular especialmente a las 16 horas. Sin embargo, las células deficientes para ATM no modificaban el punto de control G2/M en presencia de cafeína. Hay que destacar que el incremento en la fase G2/M ha estado siempre relacionado con una falta de la activación de Akt. Pero, probablemente, la evidencia más fuerte para apoyar que Akt tiene un papel en la sensibilidad asociada a ATM podría venir de un abordaje genético basado en el uso de una forma hiperactiva y una forma inactiva de Akt. Para ello las células GM9607, defectivas para ATM, fueron transfectadas con una forma inactiva o hiperactiva de Akt. Las células que fueron seleccionadas y mantenidas en cultivo con los diferentes mutantes de Akt fueron sometidas a un ensayo de viabilidad y a una comprobación de la expresión del epitopo HA (datos no mostrado).Como cabía esperar, la forma inactiva de Akt no modificaba las curvas de viabilidad mientras que la forma hiperactiva (Myr) era capaz de reestablecer la radio resistencia de una manera similar a los que presentaban los transfectantes con ATM salvaje (Fig. 4b). En resumen, estos experimentos apoyan sin lugar a dudas, un papel crítico de Akt en la radio sensibilidad asociada a ATM.

\section{Discusión}

Del presente trabajo se pueden extraer varias conclusiones. La primera conclusión clara es la interconexión entre estas dos proteínas, Akt y ATM, que presentan un papel critico en el mantenimiento de la homeostasis celular.

Desde el punto de vista mecanístico nuestro datos demuestran de forma inequívoca que ATM controla la activación completa de Akt vía el control ejercido en al serina 473, o al menos los mecanismo moleculares que determina la fosforilación de dicho residuo. No obstante, son necesarios más estudios para determinar las proteínas afectadas por ATM para controlar la actividad de Akt.

En lo referente a la resistencia a insulina nuestros datos demuestran que la falta de actividad de Akt puede ser uno de los mecanismos, que junto con otros ya descritos como $4 \mathrm{EBPI}^{18}$, pueden justificar los fenómenos de resistencia a insulina descritos en enfermos de AT.

Por otro lado en la radio sensibilidad, una de las características más interesante de los enfermos de AT, la falta de actividad de Akt posiblemente tenga una de las implicaciones más directas. Por un lado la falta de actividad de Akt ha sido relacionada con sensibilidad y la hiperactividad ha sido relacionada con resistencia ala quimio y radioterapia ${ }^{12}$. Además, los ratones nulos para la expresión de Akt han mostrado un claro patrón de radio sensibilidad ${ }^{16}$. Además, el característico incremento en G2/M observado en las células de enfermos de AT tras la exposición a radiación ionizante ${ }^{19}$, puede ser justificado por la baja/nula actividad de Akt observada en estos modelos celulares, debido a que Akt es una proteína critica en la transición del punto de control G2/M ${ }^{20}$. Por tanto, nosotros proponemos un modelo en el que la actividad de Akt, en respuesta a radiación ionizante, es controlada por ATM y otras proteínas aún desconocidas. En este sentido las PI3K convencionales no serían por tanto criticas para la activación final de Akt como ha sido demostrado en modelos de carcinoma epidermoide ${ }^{21}$. Desde un punto de vista terapéutico nuestros resultados indican el potencial radio sensibilizante de un inhibidor especifico de la activación y/o actividad de Akt. En este contexto podríamos aprovecharnos del efectos radio sensibilizante debidos a la falta de actividad de Akt sin tener los efectos perjudiciales asociados a la falta de AT.

Además, nuestra observación de una falta de actividad Akt observada en células deficientes en AT, puede servir como mecanismo parcial para otros síntomas observados en enfermos y modelos animales de AT como son el hipogonadismo o el retardo en el crecimiento como se ha observado en los ratones deficientes para Akt $1^{16}$.

En resumen y como conclusión principal, la falta de actividad o expresión del gen ATM provoca un fenotipo radios sensible y ello es debido al control que ejerce sobre la Ser 473 de la proteína Akt, quien en ultima instancia media la respuesta a la radiación 
ionizante. El potencial terapéutico de esta observación puede permitir el desarrollo de protocolos más específicos mediante el uso de agentes radio sensibilizantes.

\section{Agradecimientos:}

Esta trabajo ha sido financiado por proyectos de la Fundación Leticia Castillejo Castillo y del Fondo de Investigaciones Sanitarias (Proyecto 03/0763) para RSP y del Plan Nacional de I+D+I, Ministerio de Educación y Ciencia (Proyecto SAF2003-02604) para JMR. El trabajo de NM fue financiado por un Contrato asociado al proyecto ISCIII-Intramural (03/ESP27.)

\section{Correspondencia: \\ Dr. R. Sánchez-Prieto \\ Laboratorio de Oncología Molecular CRIB/ Facultad de Medicina Universidad de Castilla la Mancha Avda. de Almansa, s/n E-02006 Albacete E-mail: Ricardo.sanchez@uclm.es}

\section{Bibliografía}

1. Spacey SD, Gatti RA, Bebb G.The molecular basis and clinical management of ataxia telangiectasia. Can J Neurol Sci 2000; 27:184-91.

2. Shiloh Y. ATM and related protein kinases: safeguarding genome integrity. Nat Rev Cancer 2003; 3:155-68.

3. Abraham RT. Cell cycle checkpoint signaling through the ATM and ATR kinases. Genes Dev 2001; 15:2177-96.

4. Khanna KK, Lavin MF, Jackson SP, Mulhern TD. ATM, a central controller of cellular responses to DNA damage. Cell Death Differ 2001; 8:1052-65.

5. Pandita TK. ATM function and telomere stability. Oncogene 2002; 21:611-8.

6. Hunter T. When is a lipid kinase not a lipid kinase? When it is a protein kinase. Cell 1995; 83:1-4.
7. Kastan MB, Lim DS. The many substrates and functions of ATM. Nat Rev Mol Cell Biol 2000; 1:179-86.

8. Bakkenist CJ, K.astan MB. DNA damage activates ATM through intermolecular autophosphorylation and dimer dissociation. Nature 2003; 421:499-506.

9. Nicholson KM, Anderson NG. The protein kinase B/Akt signalling pathway in human malignancy. Cell Signal 2002; 14:381-95.

10. Downward J. Mechanisms and consequences of activation of protein kinase B/Akt. Curr Opin Cell Biol 1998; 10: 262-7.

11. Alessi DR, Andjelkovic M, Caudwell B, Cron P, Morrice $\mathrm{N}$, Cohen P, Hemmings BA. Mechanism of activation of protein kinase B by insulin and IGF-1. Embo J 1996; 15:6541-51.

12. Brognard J, Clark AS, Ni Y, Dennis PA. Akt/protein kinase B is constitutively active in non-small cell lung cancer cells and promotes cellular survival and resistance to chemotherapy and radiation. Cancer Res 2001; 61:3986-97.

13. Chan TO, Tsichlis PN. PDK2: a complex tail in one Akt. Sci STKE 2001, E1.

14. Barlow C, Hirotsune S, Paylor R, et al. (1996) Atm-deficient mice: a paradigm of ataxia telangiectasia. Cell 86, 159-71.

15. Cho H, Mu J, Kim JK, et al. Insulin resistance and a diabetes mellitus-like syndrome in mice lacking the protein kinase Akt2 (PKB beta). Science 22001; 92:1728-31.

16. Chen WS, Xu PZ, Gottlob K, et al. Growth retardation and increased apoptosis in mice with homozygous disruption of the Akt1 gene. Genes Dev 2001; 15:2203-8.

17. Westphal CH, Rowan S, Schmaltz C, Elson A, Fisher DE, Leder P. atm and p53 cooperate in apoptosis and suppression of tumorigenesis, but not in resistance to acute radiation toxicity. Nat Genet 1997; 16:397-401.

18. Yang DQ, Kastan MB. Participation of ATM in insulin signalling through phosphorylation of eIF-4E-binding protein 1. Nat Cell Biol 2000; 2:893-8.

19. Xu B, Kim ST, Lim DS, Kastan MB. Two molecularly distinct $\mathrm{G}(2) / \mathrm{M}$ checkpoints are induced by ionizing irradiation. Mol Cell Biol 2002; 22:1049-59.

20. Kandel ES, Skeen J, Majewski N, et al. Activation of Akt/ Protein Kinase B Overcomes a G(2)/M Cell Cycle Checkpoint Induced by DNA Damage. Mol Cell Biol 2002; 22: 7831-7841.

21. Singh B, Reddy PG, Goberdhan A, et al. p53 regulates cell survival by inhibiting PIK3CA in squamous cell carcinomas. Genes Dev 2002; 16:984-93. 